36. Likosky DS, Sorensen MJ, Dacey LJ, Baribeau YR, Leavitt BJ, DiScipio AW, et al. Long-term survival of the very elderly undergoing aortic valve surgery. Circulation. 2009;120(11 Suppl):S127-33.

\section{Discussion}

Dr Craig R. Smith (New York, NY). My disclosure is I am the surgical principal investigator for the PARTNER trial.

The authors are to be congratulated for demonstrating remarkably low mortality in octogenarians who are undergoing conventional surgical AVR. The most important implication of these findings is that transcatheter techniques should not be extended to lower-risk patients using age alone as a marker for elevated risk, which is a critical consideration in trial design and in labeling as these devices come out. So I think that is an important contribution.

First, I have a comment and a question. My comment first. I must respectfully object to the implication that MiniAVR as opposed to any other kind deserves partial credit for these excellent mortality results. It would be equally relevant to title this article "AVR in octogenarians done by varsity surgeons from Boston." Numerous retrospectively matched studies to the contrary notwithstanding, there is no randomized controlled evidence that a MiniAVR reduces mortality, there just isn't. Variables such as intensive care unit stay, length of time to discharge, and so forth have been shown, and although probably innocently, they are easily manipulated by enthusiasts.

Now, how could this be so? I will remind you of the famous internal thoracic artery study, internal thoracic artery ligation, in which when restratified according to whether the surgeon was an enthusiast or a skeptic, the enthusiast's patients had $40 \%$ greater relief of angina. So the surgeon is a powerful placebo. So when you are not talking about mortality, very powerful effects. In a more recent study from the University of Cologne, when subjects were told they were given a "lucky" ball to putt with that had been very successful in other people's hands, they sank $35 \%$ more putts. So I think we should be aware of this and remember that patients and referring physicians are listening, and embellishing these outstanding results with a link to a favorite technical trademark only moves that audience from ignorance to superstition.

Now to my question. I think you are right to be proud of achieving $3 \%$ operative mortality in a cohort reported to have an STS score of $14 \%$. This does concern me a little bit for several reasons. I would love to think that this is a benchmark for the TAVI procedure, as you suggest, but I do have some concerns. According to the methods, you included everyone aged more than 80 years having this procedure. As you probably know, in both the New York State database and the STS database, an STS score of 14 represents well less than $5 \%$ of the population. Age more than 80 years adds less than $3 \%$ to the STS score. So I have to wonder, where did those extra 11 points come from? I don't think that $10 \%$ with renal failure would do it, although I could be wrong. Many 90 -year-olds have STS scores less than 10. There is a series from Northwestern this year, 190 patients, who seem to be just as unselected as this cohort, in which the average STS score in those aged more than 80 years, there were 41 of them, was 6 . Their operative mortality was $2.4 \%$, similar to what you reported here. In the operable cohort of the PARTNER trial, with an average age of 83 years, the STS score is 11.8 , similar to the $12 \%$ in the Leipzig series you heard this morning. And any center that has been involved in this sort of thing knows that that quickly eliminates the majority of conventional AVR candidates. So I will say again, age more than 80 years adds less than $3 \%$ to the risk score. Now, in aggregate, these observations make an average STS score of 14 extremely surprising for the cohort presented, selected only by age. So how do you explain an average STS score that seems impossibly high in this unselected group?

Dr ElBardissi. That is a great question. Thank you, Dr Smith. It would be difficult for me to go through the details and identify every factor and how that contributed to the STS score of $14 \%$. I will say that $20 \%$ of our patients had reoperations, and, as you mentioned, $10 \%$ of patients had renal failure. This was a particularly sick cohort of patients, and although I would love to have how every factor contributed to that mean score, I just don't have that information right now.

Dr Smith. I wouldn't expect you to.

Dr Robert J. Cusimano (Toronto, Ontario, Canada). Along the lines of the other one, whenever we look at someone for a transcatheter valve, a lot of the times there is a calcified aorta and sometimes there is this word frailty; the reason we accept them is because of frailty. How have you been able to tease the frailty part of the whole thing, and the second question is, how many of your patients had calcified aortas and what do you do with those patients?

Dr EIBardissi. I think it is important to note that our institution is also participating in the PARTNER trial. So this is not meant to be a presentation saying everyone should have an open AVR. I think what you are identifying is what a number of studies have identified, which is there are a number of factors that aren't included in the STS score, such as patient frailty, porcelain aorta, severe liver failure, which generally are thought to contribute significantly to patient mortality, but, again, are not included in the STS score.

Patients who have a completely calcified aorta not amenable at all to cancellation are those whom we would generally refer and include in the PARTNER trial. These are highly select patients. These are obviously patients who underwent the scrutiny of surgeons and cardiologists and were deemed to be operative candidates for surgical AVR. So you can probably say that these are relatively healthy high-risk patients.

Dr Thoralf Sundt (Rochester, Minn). I appreciate that the intent of this presentation is really more to compare surgical AVR with percutaneous AVR, but, predictably, my question, much like Craig's, relates to the value of the "mini" component of this. If I understand correctly, you have sacrificed antegrade perfusion for femoral artery perfusion to gain 3 inches of sternum, and you have a fair number of strokes. Can you tell me anything about those strokes and make me feel better about pumping these people from the groin? These folks are 80 years old, and a lot of them have a lot of calcium in their descending thoracic aortas.

Dr EIBardissi. I can tell you that $4 \%$ of our patients had strokes, and I reviewed all these strokes. The majority of those were small strokes the patient recovered from. There were a couple that were pretty significant strokes. I still don't think a 4\% stroke rate in this cohort of patients, though, is really that significant and should deter someone from providing patients with a long-lasting AVR when they may very well make it through the postoperative phase with no complications. In fact, they would be likely to get through the postoperative phase with no complications. 
Dr Sundt. And I agree with you. I didn't mean to take a shot at you for the $4 \%$ rate in the primary cases or the $8 \%$ in the redos. The real question, though, is, would the stroke rate have been less if they had been perfused from the ascending aorta rather than from the groin? But I appreciate that it is difficult to answer that question.

Dr Bolman. Well, they are perfused antegrade. The patients receive percutaneous venous but central aortic cannulation.

Dr Sundt. It was only percutaneous femoral?

Dr EIBardissi. They are cannulated centrally and perfused centrally except in reoperations, in which case they are perfused peripherally through the femoral artery or they are perfused through the axillary artery, but in all primary operations they are perfused through the aorta.

Dr Sundt. I am sorry I misunderstood. Thank you very much.

Dr Hillel Laks (Los Angeles, Calif). One of the factors that was not discussed in the article on robotic mitral valve surgery that we just heard or in this article on MiniAVR was the effects of these approaches on the brain, on neurocognitive function. One of the great concerns that many surgeons have is the issue of de-airing of the heart at the end of these procedures, which has been shown by transcranial Doppler to shower the brain with microemboli, and the literature is replete with studies retrospectively that have shown $30 \%$ of patients having some neurocognitive dysfunctions. Do you know of any studies that have been done to compare these approaches, and particularly this one, in terms of neurocognitive function recovery, which is particularly pertinent to the old age group?

Dr ElBardissi. As far as neurocognitive function, if we are talking about these transient, diffuse neurocognitive dysfunction episodes, I don't know of any studies. If we are talking about acute events such as strokes or transient ischemic attacks, I can tell you that our institution did a retrospective study that was published in the Annals of Surgery and found no significant difference between the minimally invasive approach and the open approach as far as those acute events are concerned.

Dr Laks. I would like to emphasize that the incidence of clinically apparent strokes underrepresents diffuse brain injury that can result in neurocognitive dysfunction and that can be present as long as 6 months after surgery, and it is thought that many of those may be permanent. I think before we declare that these approaches are superior or equal, a randomized or equivalent type of study needs to be done looking at neurocognitive function both for robotic mitral valve surgery and for other minimally invasive approaches.

\title{
Predictive value of surgical scoring systems in determining operative risk for octogenarians undergoing aortic valve replacement
}

\author{
Marc R. Moon, MD
}

In a retrospective, single-center study, ElBardissi and associates $^{1}$ report the results of isolated aortic valve replacement (AVR) in 249 octogenarians from 1996 to 2009, during which time they performed a minimally invasive approach in almost all patients. This study does not compare the minimally invasive approach with the traditional AVR via median sternotomy, so any conclusions as to the impact of a particular surgical approach would not be reasonable. Therefore, I will make no reference to the specific surgical technique, but refer

\footnotetext{
From the Division of Cardiothoracic Surgery, Washington University School of Medicine, St Louis, Mo.

Disclosures: Author has nothing to disclose with regard to commercial support.

Address for reprints: Marc R. Moon, MD, Joseph C. Bancroft Professor of Surgery,

Division of Cardiothoracic Surgery, Washington University School of Medicine,

660 S. Euclid Ave, Box 8234, St Louis, MO 63110-1013 (E-mail: moonm@

wustl.edu).

J Thorac Cardiovasc Surg 2011;141:335-7

$0022-5223 / \$ 36.00$

Copyright (c) 2011 by The American Association for Thoracic Surgery

doi:10.1016/j.jtcvs.2010.12.015
}

only to AVR in general. The authors' specific aims included the following: (1) demonstrate that AVR can be performed safely in high-risk patients; (2) document long-term survival as a benchmark for future studies; and (3) assess the reliability of two current risk-prediction models, The Society of Thoracic Surgeons Predicted Risk of Mortality (STSPROM) and modified European System for Cardiac Operative Risk Evaluation (EuroSCORE) algorithms, ${ }^{2,3}$ hypothesizing that these current risk-prediction models "overestimate risk in appropriately chosen and optimized patients." Although the authors were successful in addressing specific aims 1 and 2, they may have fallen short in their assessment of the STS-PROM and EuroSCORE risk score algorithms.

\section{SPECIFIC AIM 1}

The authors report operative mortality of $3 \% \pm 2 \%(95 \%$ confidence limit) for octogenarians undergoing AVR during this modern era. Mean ventilator duration was $16 \pm 27$ 